\title{
Epworth Sleepiness Scale in obstructive sleep apnea syndrome - An underestimated subjective scale
}

\author{
C. Guimarães ${ }^{a, *}$, M.V. Martins ${ }^{a}$, L. Vaz Rodrigues ${ }^{a}$, F. Teixeira ${ }^{b}$, J. Moutinho dos Santos ${ }^{c}$ \\ a Serviço de Pneumologia, Centro Hospitalar de Coimbra, EPE, Coimbra, Portugal \\ b Serviço de Pneumologia e Centro de Medicina do Sono, Centro Hospitalar de Coimbra, EPE, Coimbra, Portugal \\ ' Centro de Medicina do Sono, Centro Hospitalar de Coimbra, EPE, Coimbra, Portugal
}

Received 22 November 2011; accepted 30 April 2012

\section{KEYWORDS \\ Epworth Sleepiness \\ Scale; \\ Obstructive sleep \\ apnea syndrome; \\ Subjective sleepiness}

\begin{abstract}
Excessive daytime sleepiness is a major symptom in obstructive sleep apnea syndrome (OSAS) and can be evaluated using both subjective and objective methods. The Epworth Sleepiness Scale (ESS) is a simple and validated questionnaire for assessing subjective daytime sleepiness in the context of sleep disorders. Although its subjective character may limit the accurate expression of daytime sleepiness, the clinical benefit of sequential ESS is clear and demonstrates how ESS scores evolve in individual patients and how these scores may relate to various parameters.

In this context we compared the severity of daytime sleepiness reported at baseline visit with severity of baseline sleepiness assessed, retrospectively, after treatment with automatic positive airway pressure (APAP).

We conducted a prospective study that included 66 patients evaluated in a sleep clinic diagnosed with OSAS. The diagnosis was confirmed by in-laboratory or portable sleep studies. Their mean age was 53.3 years and the majority were men $(88 \%, n=58)$. The ESS was answered during the first interview (baseline daytime sleepiness). During follow-up visits, after APAP treatment, the patient was asked to assess baseline sleepiness, retrospectively, as well as post-treatment sleepiness. The mean baseline ESS score was 11.8, mean retrospective baseline ESS 15.4, with a mean difference of 3.55 ( $p<0.001 t$-test) and post-treatment ESS 7.3. There was no significant correlation between the difference in ESS score (baseline - retrospective baseline) with the average daily (hours) use of APAP, the apnea-hypopnea index (AHI), the minimal recorded $\mathrm{SatO}_{2}$, disease duration, body mass index (BMI) and age.

Our findings confirm that the severity of subjective sleepiness reported before treatment with positive airway pressure is often underestimated by patients with OSAS.

(c) 2012 Published by Elsevier España, S.L. on behalf of Sociedade Portuguesa de Pneumologia.
\end{abstract}

\footnotetext{
is Please cite this article as: Guimarães C, et al. Escala de sonolência de Epworth na síndroma de apneia obstrutiva do sono: uma subjetividade subestimada. Rev Port Pneumol. 2012. http://dx.doi.org/10.1016/j.rppneu.2012.04.009.

* Corresponding author.

E-mail address: catarina.guimaraes@yahoo.com (C. Guimarães).
}

2173-5115/\$ - see front matter ๔ 2012 Published by Elsevier España, S.L. on behalf of Sociedade Portuguesa de Pneumologia. 


\section{PALAVRAS-CHAVE}

Escala de sonolência de Epworth;

Síndrome da apneia obstrutiva do sono; Sonolência subjetiva

\section{Introduction}

Excessive daytime sleepiness is a key symptom in patients with OSAS and represents a new major public health issue due to its repercussions. ${ }^{1}$ Sleepiness can be evaluated using subjective and objective instruments. The Multiple Sleep Latency Test (MSLT) and the Maintenance of Wakefulness Test (MWT) belong to the latter category, and the MSLT is generally considered to be the gold standard. The MSLT is based on the principle that degrees of sleepiness can be measured by how quickly one falls asleep (sleep latency) if given the opportunity to do so. ${ }^{2}$ By contrast, the MWT measures sleep latency when the subject is asked to stay awake. ${ }^{3}$ Although reliable these tests are expensive, time-consuming and impractical for widespread clinical use. The pupillographic sleepiness test, based on the evaluation of spontaneous pupillary changes in darkness, is gaining widespread use and approval for the quantitative assessment of daytime sleepiness. ${ }^{4}$ The ESS is a simple and validated method, first described in 1991, which measures the probability of falling asleep in a variety of situations. ${ }^{5-7}$ It consists of eight questions, each scored with a degree of severity ranging from 0 to 3 . This yields a total score of 0 (minimum) to 24 (maximum)..$^{6,7}$ It is easy to administer and is currently the most widely used subjective test for sleepiness. ${ }^{8-10}$ There are many published reports about the correlation between ESS scores and MSLT scores. The agreement between objective and subjective methods of sleepiness evaluation has been found to be only moderate. . $^{6,10-12}$

Excessive sleepiness is an important symptom when deciding whether patients with OSAS should be treated and not all patients with OSAS complain of it. There are some studies that discuss the use of positive airway pressure in subjects without sleepiness ${ }^{13}$; however, the subjective character of the ESS may condition the real perception of pretreatment levels of sleepiness.

\section{Objective}

The aim of this study was to compare the severity of sleepiness reported at baseline visit with severity of baseline sleepiness measured, retrospectively, after effective treatment with APAP using the same clinical instrument (ESS). Possible mechanisms underlying this difference were also explored.

\section{Material and methods}

We performed a prospective study that included consecutive patients observed in a sleep clinic and diagnosed with OSAS by in-laboratory polysomnography (Level I of ASDA), Somnostar ${ }^{\circledR}$, or home sleep studies (level III of ASDA), ${ }^{14}$ Embletta $^{\circledR}$ and Stardust ${ }^{\circledR}$. 
Table 1 Characteristics of the EES score and AHI.

\begin{tabular}{|c|c|c|c|c|}
\hline & Baseline (pretreatment) & Retrospective baseline & Post-treatment & $p$ \\
\hline ESS (mean $\pm \mathrm{st}$ ) & $11.8 \pm 5.3$ & $15.4 \pm 5.6$ & $7.3 \pm 4.7$ & $<0.001^{\mathrm{a}}$ \\
\hline ESS $<10(n)$ & 32 & 12 & 47 & $<0.001^{\mathrm{b}}$ \\
\hline $\mathrm{AHI}($ mean $\pm \mathrm{st})$ & $34.3 \pm 17.6$ & & $2.9 \pm 1.3$ & $<0.001^{\mathrm{c}}$ \\
\hline
\end{tabular}

All patients had an $\mathrm{AHI} \geq 10$ and an $\mathrm{ESS} \geq 10$ was considered to represent abnormal daytime sleepiness. ${ }^{6}$ In follow-up visits we analysed the minimal $\mathrm{SatO}_{2}$, perception of pre-treatment disease duration (understood as the number of years of witnessed apneas), residual $\mathrm{AHI}$ and adherence to APAP treatment. We excluded patients with other sleep disorders associated with daytime sleepiness such as restless legs syndrome and chronic sleep deprivation and those with unresolved sleep apnea (residual $\mathrm{AHI}>5$ ).

Patients routinely answered ESS on their first interview and again during follow-up visits (3-6 months of APAP treatment). During the follow-up consultation they were given 2 questionnaires and asked to assess post-treatment, as well as baseline (retrospective evaluation) severity of sleepiness. SPSS 17.0 was used for the statistical analysis.

\section{Results}

We included 66 patients, with a mean age of $53.3 \pm 10.3$; 23-72 ( $x \pm \mathrm{sd}$; min-max) years, of whom $88 \%$ were men $(n=58)$ and $12 \%$ women $(n=8)$. Their mean BMI was $31.3 \pm 5$; $22.4-52.9 \mathrm{~kg} / \mathrm{m}^{2}$. The mean baseline ESS score (pretreatment) was $11.8 \pm 5.3 ; 0-23$. A number of patients did not show scores comparable with abnormal daytime sleepiness $(n=32$, ESS $<10)$. The majority of subjects $(n=59)$ underwent home cardiorespiratory study and 7 laboratory polysomnography. As a group they had a $\mathrm{AHI}$ of $34.3 \pm 17.6$; 11.5-85 events/h, a minimal recorded $\mathrm{SatO}_{2}$ of $77.2 \pm 7.6$; $60-90 \mathrm{mmHg}$ and a perception of the disease duration of $7.4 \pm 5.6 ; 1-30$ years. There was no correlation between the ESS score and these parameters.

All patients were treated with APAP with a mean delivered pressure of $8.6 \mathrm{~cm} \mathrm{H}_{2} \mathrm{O}$. The mean daily use of APAP was $5.9 \pm 1.3 ; 2.5-8.5 \mathrm{~h}$, and 35 patients $(53 \%)$ had daily compliance $\geq 6 \mathrm{~h}$. Residual AHI was $2.9 \pm 1.3 ; 1-5$ events/h. After treatment with APAP the mean ESS score was $7.3 \pm 4.7 ; 0-21$ $(p<0.001 t$-test). Table 1 represents the basic characteristics of EES scores and AHI.

The retrospective baseline ESS score was 15.4 \pm 5.6 ; $2-25$, with a mean difference between the initial and retrospective score of 3.55 ( $p<0.001 t$-test). After receiving APAP treatment the retrospective baseline ESS score was $<10$ in only 12 patients. Twenty-three percent of all patients had initial 'normal' scores and retrospective 'sleepy' scores. In this subgroup of patients there was a significant difference in age, with a younger group having a higher retrospective score $(p<0.001 t$-test). The differences (statistical significance) between baseline, retrospective baseline and post-treatment ESS score are represented in Fig. 1.

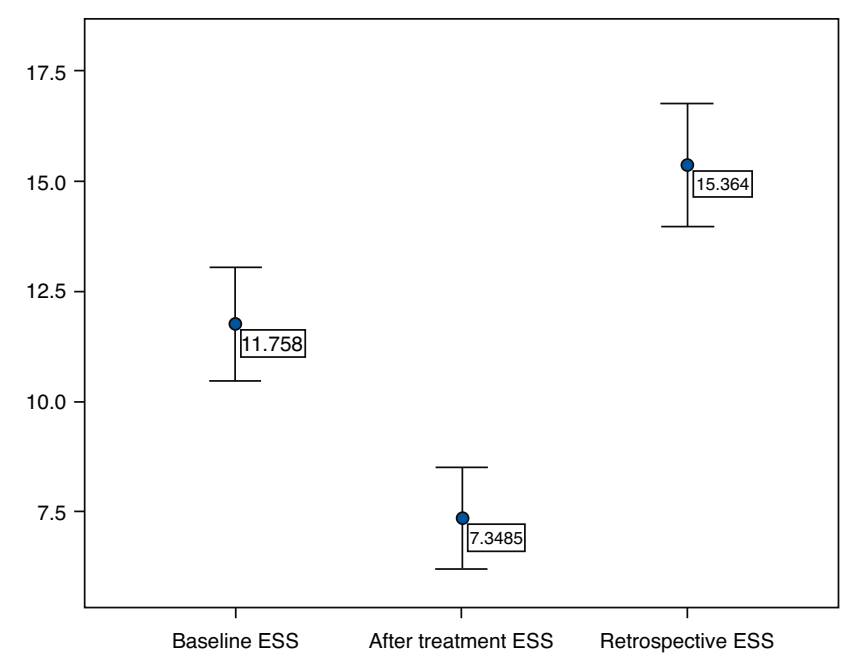

Figure 1 Epworth score.

There was no significant correlation between the difference in the ESS score (baseline - retrospective baseline) and the average daily (hours) use of APAP $(p=0.066$, Pearson), the $\mathrm{AHI}(p=0.315$, Pearson), the minimal recorded $\mathrm{SatO}_{2}(p=0.273$, Pearson), perceived length of the disease ( $p=0.111$, Pearson), age $(p=0.103$, Pearson) and BMI $(p=0.060$, Pearson). There was no difference between the retrospective and post-treatment ESS scores in compliant and non-compliant patients ( $p=0.201$ and $p=0.069 t$-test).

The difference in the ESS scores, baseline - retrospective baseline and baseline - post-treatment, were significantly correlated ( $r=0.667, p<0.001$, Pearson; Fig. 2) illustrating that the greater the symptom relief the higher the scores attributed retrospectively.

\section{Discussion}

As expected our population shows a predominance of middle-aged men, results that are in keeping with the prevalence of OSAS. ${ }^{15}$

In accordance with other studies ${ }^{16,17}$ there was no correlation between the initial ESS score and the AHI, emphasizing the subjectivity of this scale.

A large number of patients had not recognized the degree of sleepiness experienced before treatment until they had received APAP treatment: $48 \%(32 / 66)$ of the patients scored the Epworth scale $<10$ before treatment, a number that reduced to $18 \%(12 / 66)$ when answered retrospectively. The perception of sleepiness determined before APAP treatment 


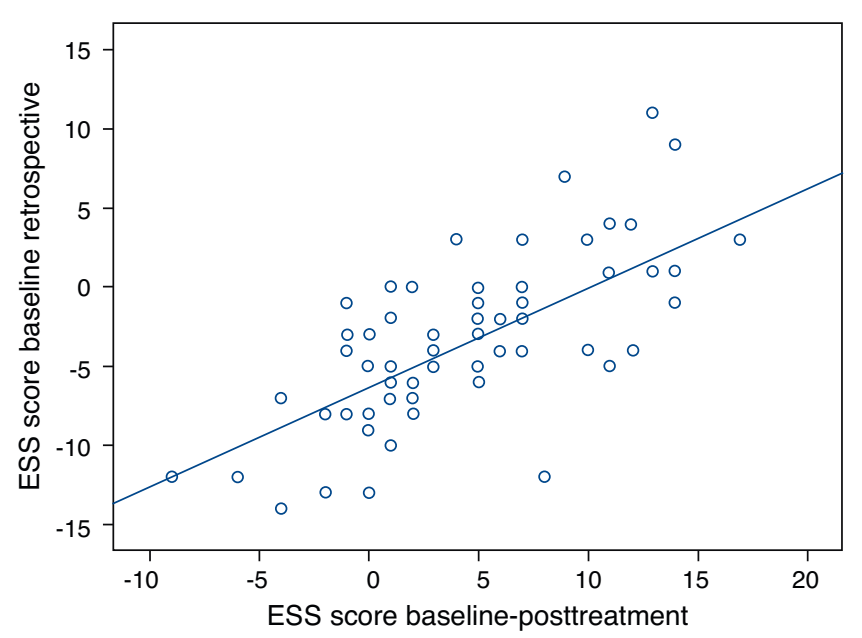

Figure 2 Correlation between ESS scores.

changed significantly after treatment. The mean ESS score was significantly increased from 11.8 to 15.4. Engleman et al. ${ }^{18}$ published data that suggest a high prevalence of symptom minimization before treatment in OSAS patients, in 99 patients median ESS score for pre-treatment sleepiness increased from 12 initially to 14 retrospectively. These authors did not offer an explanation for this outcome.

Howard et al. ${ }^{19}$ and Golembiewski et al. ${ }^{20}$ were the first to describe the concept of response shift, defined as a change in one's internal perception or understanding over time. It is a naturally occurring process believed to be part of natural coping and adaptive mechanisms. ${ }^{21}$ When these patients experienced positive changes in health status it reinforced the significance of the initial symptoms. Chin et al. ${ }^{22}$ set out to evaluate the response shift in ESS scores in 31 OSAS patients before and after continuous positive airway pressure (CPAP). They tested the AHI, the severity of desaturation and the duration of CPAP use but they did not find any mechanism for the response shift in patients with OSAS.

We did not find any significant correlation between the variables tested and the difference in ESS scores, so we cannot conclude that this difference was due to age, BMI, average daily use of APAP, AHI, minimal recorded $\mathrm{SatO}_{2}$ or supposed length of disease. However, the subgroup with higher retrospective baseline ESS scores was younger than the rest of our study group. The strong positive correlation between ESS scores, baseline - retrospective baseline and baseline - post-treatment indicates that the greater the improvement in daytime sleepiness after APAP treatment, the better their retrospective perception of sleepiness. The concept of response shift applies here. Only after effective treatment are patients able to correctly assess their degree of initial sleepiness.

Daytime sleepiness in OSAS is of growing interest and significance to sleep physicians. It is accepted that the diagnosis of OSAS should not depend on a particular level of $\mathrm{AHI}$ alone, but also take into account the degree of functional impairment associated with sleepiness. The ESS is the best available tool for the physician to estimate the patient's perceived sleepiness and has been extensively used to group patients according to the severity of sleepiness and determine whether patients with OSAS are treated or not. ${ }^{13}$ Although our sample size is small, our results indicate that patients underestimate the severity of their sleepiness and there is a risk in using such a subjective measure to validate the decision to treat. A more objective measure is needed to substantiate these decisions pertaining to sleepiness.

As with any questionnaire-based instrument, the ESS is limited by the subject's ability to read and understand the questionnaire and to answer the questions honestly. Patients may also deny clinically significant sleepiness because of social stigma and potential job loss. Perhaps the scale should be completed by both the patient and their partner in order to minimize problems and underestimated sleepiness.

ESS scores can also be used to predict the likelihood of long-term compliance with CPAP $^{23}$ and in our study there was a significant relief of sleepiness after treatment.

\section{Conclusions}

Daytime sleepiness is common but often unrecognized in OSAS and the ESS is currently the most widely used subjective test for determining its severity. Our results show that the degree of subjective sleepiness recorded before treatment was frequently underestimated by patients with OSAS. Sleepiness scores determined before treatment changed significantly after treatment, as measured by baseline ESS scores before and after (retrospective baseline) APAP treatment. There is considerable individual variation not only in susceptibility but also in sleepiness perception among patients with OSAS and no cause was found to justify this variability.

\section{Conflicts of interest}

The authors have no conflicts of interest to declare.

\section{References}

1. Flemons WW, Buysse D, Redline S, Pack A, Strohl K, Wheatley J, et al. Sleep-related breathing disorders in adults: recommendations for syndrome definition and measurement techniques in clinical research. The Report of an American Academy of Sleep Medicine Task Force. Sleep. 1999;22:667-89.

2. Carskadon MA, Dement WC, Mitler MM, Roth T, Westbrook PR, Keenan S. Guidelines for the Multiple Sleep Latency Test (MSLT): a standard measure of sleepiness. Sleep. 1986;9:519-24.

3. Mitler M, Gujavarty KS, Browman CE. Maintenance of wakefulness test: a polysomnographic technique for evaluating treatment in patients with excessive somnolence. Electroencephalogr Clips Neurophysiol. 1982;153:658-61.

4. Wilhelm B, Giedke H, Ludtke H, Bittner E, Hofmann A, Wilhelm $\mathrm{H}$. Daytime variations in central nervous system activation measured by a pupillographic sleepiness test. J Sleep Res. 2001;10:1-7.

5. Johns MW. Daytime sleepiness, snoring, and obstructive sleep apnea. The Epworth Sleepiness Scale. Chest. 1993;103:30-6.

6. Johns MW. A new method for measuring daytime sleepiness: the Epworth Sleepiness Scale. Sleep. 1991;14:540-5.

7. Santos CR. Avaliação da sonolência diurna excessiva: Adaptação cultural e linguística da escala de sonolência de Epworth para a população portuguesa. Monografia de licenciatura em neurofisiologia. Escola Superior de Tecnologia do Porto, unpublished; 2001. 
8. Johns MW. Sleepiness in different situations measured by the Epworth Sleepiness Scale. Sleep. 1994;17:703-10.

9. Briones B, Adams N, Strauss M, Rosenberg C, Whalen C, Carskadon M, et al. Relationship between sleepiness and general health status. Sleep. 1996;19:583-8.

10. Chervin RD, Aldrich MS, Pickett R, Guilleminault C. Comparison of the results of the Epworth Sleepiness Scale and the Multiple Sleep Latency Test. J Psychosom Res. 1997;42:145-55.

11. Sangal RB, Mitler MM, Sangal JM. MSLT, MWT and ESS: indices of sleepiness in 522 drug-free patients with narcolepsy [Abstract]. US Modafinil in Narcolepsy Multicenter Study Group. J Sleep Res. 1997;26:492.

12. Johns MW. Sensitivity and specificity of the Multiple Sleep Latency Test (MSLT), the Maintenance of Wakefulness Test and the Epworth Sleepiness Scale: failure of the MSLT as a gold standard. J Sleep Res. 2000;9:5-11.

13. Barbé $F$, Duran-Cantolla J, Carmona C, de la Peña $M$, Chiner EJF, Masa JF, et al. Effect of CPAP treatment on the incidence of cardiovascular events and hypertension in non-sleepy OSAS patients. A long-term RCT. Am J Respir Crit Care Med. 2010;181:A5559.

14. Ferber R, Millman R, Coppola M, Fleetham J, Murray CF, Iber C, et al. ASDA standards of practice: practice parameters for the use of portable recording in the assessment of obstructive sleep apnea. Sleep. 1994;17:378-92.

15. Young T, Peppard PE, Gottlieb DJ. Epidemiology of obstructive sleep apnea. A population health perspective. Am J Respir Crit Care Med. 2002;165:1217-39.
16. Sauter C, Asenbaum S, Popovic R, Bauer H, Lamm C, Klosche G, et al. Excessive daytime sleepiness in patients suffering from different levels of obstructive sleep apnoea syndrome. J Sleep Res. 2000;9:293-301.

17. Duran J, Esnaola S, Rubio R, Iztueta A. Obstructive sleep apnea-hypopnea and related clinical features in a population based sample of subjects aged 30 to $70 \mathrm{yr}$. Am J Respir Crit Care Med. 2001;163:685-9.

18. Engleman HM, Hirst WS, Douglas NJ. Under reporting of sleepiness and driving impairment in patients with sleep apnoea/hypopnoea syndrome. J Sleep Res. 1997;6:272-5.

19. Howard G, Ralph K, Gulanick N, Maxwell S, Nance S, Gerber $\mathrm{S}$. Internal invalidity in pretest-posttest self-report evaluations and a reevaluations of retrospective pretests. Appl Psychol Meas. 1979;3:1-23.

20. Golembiewski R, Billingsley K, Yeager S. Measuring change and persistence in human affairs: types of change generated by $O D$ designs. J Appl Behav Sci. 1976;12:133-57.

21. McPhail S, Haines T. The response shift phenomenon in clinical trials. J Clin Res Best Pract. 2010;6.

22. Chin K, Fukuhara S, Takahashi K, Sumi K, Takaya K, Nakamura T, et al. Response shift in perception of sleepiness in obstructive sleep apnea-hypopnea syndrome before and after treatment with nasal CPAP. Sleep. 2004;27.

23. McArdle N, Devereux G, Heidarnejad H, Engleman HM, Mackay TW, Douglas NJ. Long-term use of CPAP therapy for sleep apnea/hypopnea syndrome. Am J Respir Crit Care Med. 1999;159:1108-14. 